\title{
Um século de religiosidade Pentecostal: algumas notas sobre a irrupção, problemas e desafios do fenômeno pentecostal
}

A century of Pentecostal religiosity: some notes on the irruption, problems and challenges of the Pentecostal phenomenon

A presente edição da revista Horizonte se ocupa de um tema que, há cerca de cinquenta anos, frequenta as preocupações dos estudiosos dos fenômenos religiosos tanto no Brasil como no exterior: a emergência e expansão contínua das formas eclesiológicas conhecidas como igrejas pentecostais e originadas no amplo arco do denominacionalismo protestante norte-americano.

A impressionante e incessante multiplicação dessas comunidades entre nós, a partir da ação dos jovens imigrantes suecos Gunnar Vingren e Daniel Berg em Belém do Pará, em 1911, e do operário de origem italiana Luigi Francescon em São Paulo, em 1910, que deram origem, respectivamente, às Assembléias de Deus e à Congregação Cristã do Brasil, fizeram do Brasil o maior país pentecostal do mundo. Ambas vertentes procedem do movimento inicial inaugurado pelo jovem pastor negro William Seymour em Los Angeles (EUA), em 1906, cujo impacto gerou um movimento eclesial de variadas facetas e múltiplas expressões comunitárias, teologicamente unidas na ênfase no poder do Espírito e no falar em línguas estranhas (glossolália). Expandindo-se rapidamente pelas mais diferentes sociedades abrange, atualmente, cerca de um quarto do total de dois bilhões de adeptos do Cristianismo em todo o mundo. Alguns estudiosos o classificam como a quarta fase da história da Igreja Cristã, depois da Reforma, do Movimento Missionário do século XIX e do Movimento Ecumênico no século XX.

\footnotetext{
${ }^{*}$ Doutor em Teologia pela Univ. de Hamburg, Alemanha. Prof. no Programa de Pós-Graduação em Ciência da Religião da Univ. Federal de Juiz de Fora (UFJF), MG. Pastor da Igreja Presbiteriana Unida do Brasil. Editor da revista eletrônica "Tempo e Presença", de "Koinonia - Presença Ecumênica e Serviço".País de origem: Brasil. E-mail: zwli@ powerline.com.br
} 
Contudo, tanto do ponto de vista histórico como da perspectiva teológica, seria errôneo afirmar que o movimento pentecostal, com sua ênfase na contemporaneidade dos dons do Espírito e no Batismo do Espírito Santo, só teria surgido nas imediações do segundo milênio. Basta um breve recorrido pela história da Igreja cristã para se perceber incontáveis manifestações de caráter místico-emocional de tipo pentecostal que pontilharam a trajetória do Cristianismo desde seus inícios e por toda a parte em que a igreja cristã veio a estabelecer-se.

No Brasil o movimento pentecostal, nos seus inícios, tanto na região Norte como no Sudeste, aparentemente permaneceu isolado e silencioso, sendo ignorado como religião de pobres "primitivos e ignorantes", tanto pela Igreja Católica como pelas igrejas do Protestantismo "histórico", até à década de trinta. Nesse período, no entanto, ele foi-se expandindo, tanto pela região Nordeste como pelas periferias de S. Paulo e Rio de Janeiro, ao mesmo tempo em que consolidava sua estrutura organizacional e construía seu peculiar ethos religioso em total empatia com as demandas populares. Como assinala o sociólogo Alexandre C. de Souza (2004, p. 23):

\footnotetext{
O pentecostalismo assimilou doutrinariamente a exclusão social, legitimando-a mediante estatuto sagrado, construindo uma visão de mundo pautada no extravasamento das dores e das carências pelo emocional, crendo na vigência de outra linguagem, que não a deste mundo, uma língua estranha a todos os códigos linguísticos, o apego às curas e às libertações operadas milagrosamente. Essas manifestações tiveram repercussão social e acabaram sendo rotuladas pelas classes privilegiadas como características de uma religião bizarra.
}

Na medida em que se constituiu como uma manifestação religiosa dos pobres, e a partir de sua situação de pobreza, o movimento pentecostal se inseriu plenamente no contexto sociocultural brasileiro e aqui se desenvolveu como uma prática religiosa que exprimia os sofrimentos, as angústias e as esperanças dos setores populares. Como assinala ainda o autor supracitado:

Depois da quase-extinção do culto autóctone praticado pelos indígenas, após o desembarque da nova religião imposta pelos portugueses, foram os pentecostais, e antes deles os africanos, que instituíram uma religião que exprimia a dor, os anseios, os sonhos e os desafios do pobre. A alma do pobre estava refletida no rito, na linguagem, na teologia, na concepção de Deus, na formação e no desempenho da liderança e no estatuto do corpo de fiéis (SOUZA, 2004, p. 24). 
Ao longo desses cem anos de presença e interação no interior da sociedade brasileira o movimento pentecostal, a partir de sua diversidade de formas organizacionais e em resposta às demandas provocadas pelas mudanças sofridas pela sociedade, expressou-se em diferentes formas de representação de seus conteúdos religiosos. Nos seus começos preocupou-se com as manifestações dos dons do Espírito como elementos indispensáveis para o aprofundamento da vivência espiritual da igreja e sua obra missionária. A partir da década de cinqüenta, o que vai marcar a experiência pentecostal será a busca dos resultados da ação do Espírito na forma da cura de enfermidades e libertação espiritual das forças malignas que subjugam e fazem sofrer as pessoas. Inaugura-se nesse período o uso do rádio e das grandes concentrações populares. A partir do final da década de setenta um terceiro elemento é acrescentado aos dois primeiros, qual seja a difusão da crença de que a operação do Espírito nas mentes e corações liberta os indivíduos da pobreza, da miséria e da opressão demoníaca. Está assim constituída a tríade cura, exorcismo e prosperidade que caracterizará daí por diante o chamado neopentecostalismo. Esses três momentos característicos da trajetória do pentecostalismo vão ser descritos pelo sociólogo Paul Freston como 'ondas' diferentes e sucessivas que modificam e ampliam a resposta pentecostal às demandas postas pelos setores empobrecidos da sociedade, vitimados, nesse período, pela imposição de políticas econômicas neoliberais.

Na segunda metade do século XX vamos observar o movimento pentecostal avançando com ímpeto no interior da sociedade brasileira que se encontra em processo de desenvolvimento socioeconômico desigual e perverso que privilegia, via uma modernização seletiva, as velhas estruturas de poder econômico e político ao mesmo tempo em que sacrifica, pela exclusão econômica e a marginalização política, a grande maioria da população do país. Exposta a uma luta desigual e cruel pela sobrevivência, esta população se vê tangida para os centros urbanos em busca de trabalho e onde é tolhida num processo de urbanização caótico e desumano. É entre essa população em permanente aflição, desgarrada de seus valores mais caros, que a mensagem pentecostal deita raízes, oferecendo toda sorte de lenitivos para o sofrimento (que vai buscar no tesouro comum 'indígena-afrocatólico' da matriz religiosa brasileira, ainda que com sinais invertidos) e estruturas de sentido para os desorientados, mas sem atentar, no entanto, para as causas reais que 
produzem continuadamente o mal estar social que caracteriza a sociedade como um todo. Como assinala Antonio G. de Mendonça,

parece haver um universo mágico que perpassa a sociedade em que espíritos benéficos e maléficos são exorcizados por heróis construídos pela mídia nas classes privilegiadas e por lideranças religiosas nas camadas periféricas da sociedade. O sucesso desta ou daquela religião repousa nos ajustes feitos entre a mensagem e a prática religiosa e os desejos individuais que se opõem às forças do imaginário. (MENDONÇA, 1998, p.50).

Esta suspeita, levantada pelo professor Mendonça, foi sistematizada com rigor e vigor pelo sociólogo J. Bittencourt Filho ao estabelecer a "existência, no bojo da matriz cultural, de uma matriz religiosa, que provê um acervo de valores religiosos e simbólicos característicos, assim como propicia uma religiosidade ampla e difusa entre os brasileiros." (BITTENCOURT FILHO, 2003, p.17). Num processo multissecular teria ocorrido "a gestação de uma mentalidade religiosa média dos brasileiros, uma representação coletiva que ultrapassa mesmo a situação de classe em que se encontrem” (Ibid., p.41). Essa matriz religiosa teria sido, então, resultante da convergência de valores e práticas religiosas advindas do catolicismo ibérico, da religiosidade indígena, das religiões africanas e, um pouco mais tarde, se acrescentaria a contribuição do Espiritismo europeu, da magia e de fragmentos do Catolicismo romanizado. Para o autor, o Catolicismo e as instituições eclesiásticas protestantes "históricas" reagiram de forma diferenciada a essa mentalidade. O primeiro procurou assimilá-la, convivendo com o sincretismo peculiar dessa matriz religiosa. Os protestantes rejeitaram-na in totum como expressão do mal, do pecado e da heresia e, com essa atitude, ajudaram a recalcá-la ainda mais no plano inconsciente. Por sua vez os Pentecostalismos, segundo o autor,

reprocessaram a religiosidade de origem matricial, apondo-lhe sinais valorativos. Em outras palavras: ao invés de rejeitar esse sistema de crenças do senso comum, discriminaram e classificaram aquilo que pertenceria ao domínio de Deus e aquilo que se situaria na jurisdição do Diabo. A rigor, com esse procedimento, os pentecostalismos ensejam que a Matriz Religiosa Brasileira permaneça intacta. Esta seria apenas cuidadosamente realocada num novo esquema religioso. (BITTENCOURT FILHO, 2003, p.44).

Por outro lado, esta mensagem pentecostal, em sua interação com a cultura dos 
segmentos por ela atingidos, entrou num processo de adaptação e transformação permanente que, pouco a pouco, foi lhe escoimando todos aqueles elementos de difícil ou impossível adaptação. Por isso se pode dizer que a realidade pentecostal hoje, deitada no "berço esplêndido" da tradicional religiosidade brasileira, acabou por nacionalizar (culturalmente falando) o que restou do Protestantismo em seu choque com a cultura brasileira. De forma emblemática, o antropólogo Pierre Sanchis sintetiza esse sincretismo cultural religioso:

O mundo dos espíritos é tornado presente nos cultos dramáticos de 'libertação' e 'expulsão'. Não se trata, aliás, de espíritos quaisquer, mas daqueles bem conhecidos dos fiéis candomblecistas ou umbandistas: os exús e pombagiras, transformados em demônios e chamados a manifestar-se, para serem humilhados e destituídos. Reconhecimento de um mundo maligno de espíritos, que libera em parte a consciência de sua responsabilidade moral, transformando em celebração da liberdade a radicalidade da 'conversão'. Nesses casos todos, um universo amplamente familiar é reconhecido, instrumentalizado, mas vê seus sinais invertidos. Não se trata de ignorar o universo religioso popularmente implantado, mas de penetrá-lo, mesmo se para explodi-lo: do encantamento à assombração. (SANCHIS, 1997, p.125).

Nesse contexto a 'permanente insurreição emocional' (CORTEN, 1996, p.12) produzida pelos Pentecostalismos, que cura e restaura a dignidade e o amor próprio dos pobres, rejeitados e desesperados de nossa sociedade, em que pesem todos os aspectos negativos que possam encerrar, apresenta para as igrejas do Protestantismo "histórico" e para a Igreja Católica o desafio de uma revisão histórica de suas teologias e práticas pastorais que seja capaz de transformá-las novamente em comunidades acolhedoras e integradoras, de novo capazes de “ouvir o que o Espírito diz às Igrejas [...].” (Apoc. 3,13).

\section{REFERÊNCIAS}

BITTENCOURT FILHO, José. Matriz religiosa brasileira. Religiosidade e mudança social. Petrópolis: Vozes; Rio de Janeiro: Koinonia, 2003.

CORTEN, André. Os Pobres e o Espírito Santo: o pentecostalismo no Brasil. Petrópolis: Vozes, 1996. 
MENDONÇA, Antônio Gouvêa. Religiosidade no Brasil: imaginário, pós-modernidade e formas de expressão. Estudos da religião. Estratégias religiosas na sociedade brasileira, São Bernardo do Campo: UMESP, v. 12, n. 15, p. 39-50, dez. 1998.

SANCHIS, P. Pentecostalismo e cultura brasileira. Religião \& Sociedade, Rio de Janeiro, v. 18, n. 2, p. 123-126, dez.1997.

SOUZA, Alexandre C. de. Pentecostalismo: de onde vem, para onde vai? Um desafio às leituras contemporâneas da religiosidade brasileira. Viçosa: Ultimato, 2004. 